Gut, 1987, 28, 142-145

\title{
Endoscopic sphincterotomy and surgical approaches in the treatment of the 'sump syndrome'
}

\author{
U A MARBET, G A STALDER, H FAUST, F HARDER, AND K GYR \\ From the Division of Gastroenterology, Departments of Internal Medicine and Surgery, University of Basel, \\ Basel, Switzerland
}

SUMmaRY The 'sump syndrome' is a rare, late complication of choledochoenterostomies. We observed 13 patients with this syndrome. The clinical features included recurrent cholangitis, liver abscesses, and recurrent pancreatitis. Five patients were treated by surgery, eight patients endoscopically. Reviewing an average follow up period of 22 months (range 6-60) after therapeutic endoscopy and 57 months (range 1-126) after different surgical procedures, we conclude that endoscopic sphincterotomy with removal of the debris is as efficient a therapy of the 'sump syndrome' as surgical sphincteroplasty and entails a smaller risk for the patient. We therefore advocate that endoscopic papillotomy should first be tried in all cases of 'sump syndrome' in the absence of suprapapillary stricture of the bile ducts.

Standard surgical procedures for benign biliary tract diseases are papillotomy or sphincteroplasty, although choledochoenterostomy is sometimes preferred. Late failures of choledochoenterostomies are rare $(2-4 \%)^{12}$ and sometimes require surgical correction. In a side-to-side choledochoduodenostomy or a side-to-side/side-to-end choledochojejunostomy, the distal limb of the common bile duct is excluded from the draining bile flow and can function as a sump. In this poorly drained part of the choledochus between the papilla of Vater and the anastomosis, lithogenic bile, cholesterol crystals, and food particles may accumulate and new concrements may be formed, leading to complications in the biliary tract as well as in the pancreas. The resulting syndrome is characterised by a variety of symptoms such as recurrent pain, jaundice, pancreatitis, and cholangitis. For a long time, surgical therapy was the only possible treatment, but in recent years, endoscopic interventions have been advocated as well. ${ }^{3-5}$ Very little is known, however, of the long term outcome of the different therapeutic approaches.

Address for correspondence: Dr U Marbet, Dept Innere Medizin, Abteilung Gastroenterologie, Kantonsspital, Petersgraben 6/Hebelstr 2, Basel, CH4031, Switzerland.

Received for publication 13 June 1986
We report our experience with 13 patients presenting with features of the 'sump syndrome' and describe their clinical outcome after endoscopic and/or operative treatment.

\section{Methods}

PATIENTS

The charts of all patients with choledochoenterostomy who were evaluated by endoscopic retrograde cholangiopancreatography between 1978 and 1985 were reviewed for the presence of 'sump syndrome'. The 'sump syndrome' was defined as the combination of radiological presence of debris and calculi in the choledochal limb between the choledochoenteral anastomosis and the papilla of Vater together with recurrent clinical symptoms such as recurrent pain, jaundice, cholangitis, liver abscess formation, and pancreatitis. Their treatment and clinical outcome are presented and the results compared.

Thirteen patients (three men, 10 women, age 40-80 years (mean 65 years)) in whom a choledochoenterostomy had been done for recurrent choledocholithiasis showed diagnostic evidence of the 'sump syndrome'. Nine of them had a previous choledochoduodenostomy and four a choledochojejunostomy. (One patient additionally had surgical papillotomy.) The diagnosis of 'sump syndrome' was 
made between one and 25 years after choledochoenterostomy with an average of 11 years. Clinical symptoms, however, were already present for many years in all patients except for one with liver abscess 25 years after choledochoduodenostomy without previous classical symptoms. The patients' clinical findings at the time of diagnosis of 'sump syndrome' were recurrent colicky-like pain (six), recurrent cholangitis (eight), complicated by spondylodiscitis in one case, liver abscesses (two), recurrent jaundice (four), and recurrent pancreatitis (three). Cholangitis and pancreatitis were diagnosed by characteristic clinical signs and confirmatory laboratory data.

All patients underwent endoscopic retrograde cholangiopancreatography (ERCP) and one patient additionally had a percutaneous transhepatic cholangiography at the time of presentation. The anastomotic size of the choledochoduodenostomy was estimated by endoscopy to be $1-2 \mathrm{~cm}$ in diameter. The anastomotic size of the choledochojejunostomy was radiologically estimated to be widely open in three of four patients, but narrow (4 $\mathrm{mm}$ in diameter) in one patient. Intermittent obstruction by sludge and calculi was possible in at least 10 of the patients. Dilatation of the distal choledochal limb with the sump occurred in all patients. Dilatation of the proximal biliary tree was radiologically seen in nine of 13 patients. Antibiotics were prophylactically given (usually Ceftriaxon $2 \mathrm{~g}$ iv).

\section{CORRECTIVE TREATMENT}

Five patients were operated by sphincteroplasty with closure of the anastomosis (two), sphincteroplasty alone (two), and modification of a choledochoduodenostomy into a side-to-end choledochojejunostomy (one). Surgery was done in these patients because of prepapillary stenosis of the choledochus (two patients), because endoscopic papillotomy was not yet available (two patients), and because of personal preference of the responsible physician (one patient). Eight patients were treated endoscopically by sphincterotomy and removal of debris and calculi by Dormia baskets and flushing. The size of the papillotomy was $1.5-2 \mathrm{~cm}$ in seven patients and less than $1 \mathrm{~cm}$ in one patient.

\section{FOLLOW UP}

No immediate complications were noted; however, one patient, referred by an outside hospital who presented with septic shock caused by cholangitis, did not improve after endoscopic papillotomy. Therefore surgical drainage by $T$ tube was carried out two days later. Despite drainage, antibiotics, and intensive supportive care the patient died four days later. All other patients were regularly followed up and clinically assessed by their family doctors in collaboration with our Gastroenterological Unit after endoscopic and surgical treatment of the 'sump syndrome'. A radiological examination (five ERCP, one iv cholangiography) was repeated in six patients (five after endoscopic sphincterotomy and one after surgical sphincteroplasty) after one to 25 months and 96 months respectively. The mean follow up period was 57 months (two to 126) after surgery and 22 months (6-60) after endoscopic treatment.

\section{Results}

SURGICAL TREATMENT

Both patients with sphincteroplasty plus closure of the anastomosis were free of symptoms for a follow up period of 18 and 30 months respectively. Of the two patients with sphincteroplasty alone, one was free of symptoms for two months, but the other developed liver abscesses 30 months later despite good drainage of the bile shown by ERCP. After surgical drainage of the abscesses and antibiotic treatment, the patient did not show any recurrence of symptoms for the next three years except for mild abdominal pain which was most likely caused by irritable colon syndrome.

The patient whose side-to-side choledochoduodenostomy was transformed into a side-to-end choledochojejunostomy did continue to collect debris and to form calculi in the remaining undrained limb with subsequent cholangitis and recurrent abdominal pain 72 months later. He was then treated surgically by performing a end-to-end hepaticojejunostomy, leaving the distal choledochal limb unresected. The patient has been free of symptoms now for 66 months.

\section{ENDOSCOPIC TREATMENT}

Five patients were free of symptoms for a mean of 29 months (6-60) after endoscopic papillotomy. The radiological checkup one to five months after sphincterotomy showed no evidence of debris and calculi in the choledochus in all five patients. Another patient had non-specific abdominal bloating and cramps, not identical to previous symptoms, suggestive of spastic colon (follow up for six months). Radiological examination after one month, however, showed the presence of food in the terminal limb of the choledochus. A further patient had a bout of cholangitis three years after papillotomy. The repeat ERCP showed the presence of calculi and debris in the inefficiently drained limb of the choledochus, despite a widely open papillotomy. Debris and calculi were removed by endoscopic flushing of the bile duct and the patient has remained free of symptoms since then (four months). 


\section{Discussion}

Our 13 patients showed the characteristic signs of 'sump syndrome'1-3 with recurrent colicky pain, recurrent jaundice, cholangitis, and pancreatitis as well as a radiologically demonstrable sump. Two liver abscesses in 13 patients were remarkable, most likely as a sequela of cholangitis.

It is believed that stenosis of the choledochoenteral anastomosis is of pathogenic importance in the 'sump syndrome' in addition to poor drainage of bile in the choledochal limb between the anastomosis and the papilla of Vater. ${ }^{16} \mathrm{We}$ found only one patient out of 13 with narrowing of the anastomosis, however. Intermittent obstruction because of food, debris, and calculi was possible and dilatation of the proximal bile duct was seen in nine of 13 patients. Most likely the primary event is the low filling pressure in the distal choledochus because of the well functioning anastomosis which interrupts normal distal peristalsis and drainage, thus favouring the formation of a sump with debris, calculi, and bacterial overgrowth in the inefficiently drained limb.

The principal therapeutic approach is to improve the biliary drainage of the choledochus distal to the anastomosis either endoscopically or by surgery. Our results as well as those of others (Table) show that endoscopic papillotomy can effectively control the 'sump syndrome' over a long period. Late recurrences are possible, but can be adequately treated endoscopically, again either by repapillotomy or by flushing and removal of recurrent debris and calculi.

Table The 'sump syndrome' after choledochoenterostomies. Outcome after endoscopic papillotomy

\begin{tabular}{|c|c|c|c|}
\hline Reference & $\begin{array}{l}\text { Patients } \\
\text { treated by } \\
\text { endoscopic } \\
\text { papillotomy } \\
\text { (n) }\end{array}$ & $\begin{array}{l}\text { Follow up } \\
\text { period } \\
\text { (months) }\end{array}$ & Outcome \\
\hline Barkin $1980^{4}$ & 2 & \multicolumn{2}{|c|}{$\begin{array}{l}60 \text { resp. } 18 \text { Both with relief of } \\
\text { symptoms }\end{array}$} \\
\hline Siegel $1981^{3}$ & 11 & $3-30$ & $\begin{array}{l}\text { All with satisfactory relief } \\
\text { of symptoms }\end{array}$ \\
\hline Tanaka $1983^{5}$ & 4 & $24-54$ & All with relief of symptoms \\
\hline $\begin{array}{l}\text { Present } \\
\text { observations }\end{array}$ & 8 & $6-60$ & $\begin{array}{l}5 \text { completely symptomfree } \\
1 \text { with irritable colon } \\
\text { syndrome } \\
1 \text { with single bout of } \\
\text { cholangitis treated } \\
\text { endoscopically, then } \\
\text { remained symptomfree } \\
1 \text { presented with septic } \\
\text { cholangitis, died despite } \\
\text { papillotomy and surgical } \\
\text { drainage }\end{array}$ \\
\hline
\end{tabular}

The therapeutic success after endoscopic treatment was comparable with that seen after surgical sphincteroplasty. The morbidity and mortality of surgical sphincteroplasty (morbidity 5-15\%, mortality $1.5-$ $11 \%$ ), however, are clearly higher than those of endoscopic papillotomy (morbidity $5 \cdot 5-13.5 \%$, mortality $0-1 \cdot 5 \%) .{ }^{17-11}$ We therefore believe that endoscopic papillotomy should be attempted first in patients with the 'sump syndrome', especially in the elderly with high operative risk, provided there is no suprapapillary stricture of the bile duct system. Blair et al recently suggested endoscopic dilatation of the narrow choledochoduodenal anastomosis if papillotomy is not possible, but no data on long term outcome were given. ${ }^{12}$ This procedure does not, however, improve the drainage of the distal choledochal limb.

If surgical therapy is chosen, a method improving drainage of the non-functioning distal choledochus should be done without creating a new undrained sump. Optimal surgical therapies would seem to be either sphincteroplasty with occlusion of the choledochoenterostomy or end-to-side hepatico- or choledochojejunal anastomosis.

We would like to thank Dr May Zimmerli, for her advice and correcting the manuscript as well as Mrs Carita Frei for her secretarial help.

\section{References}

1 Kune GA, Sali A. Biliary-intestinal operations. In: Kune GA, Sali A, eds. The practice of biliary surgery. Oxford: Blackwell, 1980: 376-98.

2 de Almeida AM, Cruz AG, Aldeia FJ. Side-to-side choledochoduodenostomy in the management of choledocholithiasis and associated disease. Facts and fiction. Am J Surg 1984; 147: 253-59.

3 Siegel JH. Duodenoscopic sphincterotomy in the treatment of the 'sump syndrome'. Dig Dis Sci 1981; 26: 922-28.

4 Barkin JS, Silvis S, Greenwalk R. Endoscopic therapy of the 'sump' syndrome. Dig Dis Sci 1980; 25: 597-601.

5 Tanaka M, Ikeda S, Yoshimoto H. Endoscopic sphincterotomy for the treatment of biliary sump syndrome. Surgery 1983; 93: 264-67.

6 Weed TE, Blalock JB. 'Sump syndrome' after choledochoduodenostomy. South Med J 1982; 75: 370-2.

7 Strunk E, Bünte $\mathbf{H}$, Kautz G, van Husen N. Chirurgische oder endoskopische Papillotomie? Med Klin 1979; 74: 1849-54.

8 Weber KB, Gyr K, Stalder GA. Endoskopische Papillotomie. Schweiz Med Wochenschr 1982; 112: 1545-9.

9 Leese T, Neoptolemos JP, Carr-Locke DL. Successes, failures, early complications and their management 
following endoscopic sphincterotomy: results in 394 consecutive patients from a single centre. $\mathrm{Br} J$ Surg 1985; 72: 215-9.

10 Mustard R, Mackenzie R, Jamieson C, Haber GB. Surgical complications of endoscopic sphincterotomy. Can J Surg 1984; 27 : 215-7.
11 Seifert E, Gail K, Weismüller J. Langzeitresultate nach endoskopischer Spinkterotomie. Dtsch Med Wochenschr 1982; 107: 610-4.

12 Blair AJ, Leung JWC, Cotton PB. Endoscopic treatment of stomal stenosis after choledochoduodenostomy: Preliminary report. Surgery 1985; 97: 487-9. 